\title{
SIMAIES - DESENVOLVIMENTO E DISCUSSÃO DE UMA FERRAMENTA PARA REGISTRAR E DIVULGAR A COOPERAÇÃO ENTRE ENTIDADES DE SAÚDE E EDUCAÇÃO
}

\author{
R.M.PINTO ${ }^{1}$, L.G.DANTAS ${ }^{2}$, L.F. SILVA ${ }^{3}$, R.A.M. VALENTIM ${ }^{4}$ \\ Instituto Federal de Educação, Ciência e Tecnologia do Rio Grande de Norte ${ }^{1}$ \\ Universidade Federal do Rio Grande do Norte Ne-4 $^{2-4}$ \\ rrafaelpinto@gmail.com ${ }^{1}$ \\ Artigo submetido em 17/08/2018 e aceito em 24/06/2019 \\ DOI: $10.15628 /$ holos.2019.7637
}

\section{RESUMO}

A Lei 12.871, que institui o Mais Médicos, determina que as instituições de educação superior responsáveis pela oferta dos cursos de Medicina e dos Programas de Residência Médica poderão firmar Contrato Organizativo da Ação Pública Ensino-Saúde (COAPES) com as secretarias de saúde, com a finalidade de viabilizar a reordenação da oferta de cursos de Medicina e de vagas de Residência Médica e a estrutura de serviços de saúde em condições de ofertar campo de prática suficiente, além de permitir a integração ensino-serviço na área da Atenção Básica. Neste sentido, o Sistema de Monitoramento e Avaliação da Integração Ensino Saúde (SIMAIES) foi desenvolvido para servir como a plataforma de gestão virtual dos contratos criados a partir do COAPES. O SIMAIES é uma ferramenta para gestores e instituições de ensino organizarem e formarem a ponte ensino-serviço comunidade nas regiões. O sistema é fruto de discussões ocorridas no Comitê Nacional dos COAPES e é peça fundamental para a propagação e correta manutenção deste recurso, otimizando o processo de avaliação e monitoramento das atividades de integração. Uma análise exploratória desta ferramenta mostrou que apesar da centralização, padronização e transparência trazida pela mesma, ainda há um fluxo burocrático a ser percorrido antes da utilização do sistema, o que pode trazer morosidade ao processo.

\section{SIMAIES - Development and Discussion About a Tool to Register and Advetise Cooperation Between Health and Education Entities}

\begin{abstract}
Law 12,871, which establishes "Mais Médicos", establishes that higher education institutions responsible for the provision of Medicine courses and Medical Residency Programs may sign an Contrato Organizativo da Ação Pública Ensino-Saúde

(Organizational Contract for Public Health Teaching) with health secretariats, the purpose of enabling the reordering of the offer of medical courses and medical residency vacancies and the structure of health services in conditions to offer sufficient field of practice, in addition to allowing the integration of teaching and service in the area of Primary Care. In this sense, the Sistema de Monitoramento e Avaliação da Integração Ensino Saúde (Monitoring and Evaluation System of
\end{abstract}

Health Teaching Integration) was developed to serve as the virtual management platform for contracts created from COAPES. SIMAIES is a tool for managers and educational institutions to organize and form the teaching-service-community bridge in the regions. The system is the result of discussions in the COAPES National Committee and is a key element for the propagation and correct maintenance of this resource, optimizing the process of evaluation and monitoring of integration activities. An exploratory analysis of this tool has shown that despite the centralization, standardization and transparency brought about by it, there is still a bureaucratic flow to be covered before using the system, which can lead to slowness in the process. KEYWORDS: Teaching-health Integration, Software Engineering, Requirements Engineering. 


\section{INTRODUÇÃO}

É comum no Brasil, já há algum tempo, a existência de políticas de integração ensino serviço-comunidade. Dentre essas políticas, existem diversas maneiras de implementação e formas de pactuação e, como um exemplo disso, temos a Pontifícia Universidade Católica do Rio Grande do Sul (PUC-RS). Esta Universidade, desde 1970, atua em conjunto com a Secretaria Municipal de Saúde de Porto Alegre (PIZZINATO, et al., 2010).

Visando homogeneizar e formalizar essas pactuações a um padrão nacional, além de dinamizá-las, surge o Contrato Organizativo de Ação Pública de Ensino-Saúde (COAPES), que teve suas diretrizes publicadas na Portaria Interministerial no 1.127 em 06 de agosto de 2015, por meio do Ministério da Saúde e da Educação. Consiste em um contrato que firma vínculos entre estabelecimentos de saúde e instituições formadoras do próprio município. Dessa forma, esse contrato possui funções e objetivos significativos, atuando como um processo de pactuação, que discute e qualifica a inserção de estudantes na rede de saúde do país e a integração ensino serviçocomunidade.

De acordo com o Ministério da Saúde (MS), pretende-se, com o COAPES, qualificar a integração ensino-serviço e a educação permanente nos territórios envolvendo pactuação entre instituições de ensino e gestores do SUS. Em outras palavras, o COAPES busca incentivar a relação ensino-serviço-comunidade contribuindo com a formação desses futuros estudantes e agindo no aprendizado deles. Desta forma, futuros trabalhadores mais aperfeiçoados e fortalecidos intelectualmente estarão trabalhando em demandas voltadas para o próprio SUS. Essa integração potencializa o desenvolvimento no campo de prática, e daqui a alguns anos os usuários que forem usufruir do SUS como beneficiados pelo COAPES poderão receber um atendimento mais capacitado.

Porém, com a implementação desta portaria, surgem algumas problemáticas. Já que o COAPES tem como objetivo ser implementado a nível nacional, como saber quais contratos/convênios foram criados e como estão registrados? Como realizar o monitoramento e

verificar a evolução de cada contratualização em uma determinada região? Como dar transparência às informações desta pactuação?

Tendo em vista essa demanda e visando resolver esta problemática, o Sistema de Monitoramento e Avaliação da Integração Ensino Saúde (SIMAIES ${ }^{1}$ ) foi desenvolvido para servir como a plataforma de gestão virtual dos contratos criados a partir do COAPES. O SIMAIES é uma ferramenta para gestores e instituições de ensino organizarem e formarem a ponte ensino serviçocomunidade nas regiões. O sistema é fruto de discussões ocorridas no Comitê Nacional dos COAPES e é peça fundamental para a propagação e correta manutenção deste recurso, otimizando o processo de avaliação e monitoramento das atividades de integração.

${ }^{1}$ http://simaies.ufrn.br

HOLOS, Ano 35, v.2, e7637, 2019 
Este trabalho tem por objetivo apresentar o Sistema de Monitoramento e Avaliação da Integração Ensino Saúde, detalhando o fluxo das tarefas e os papéis dos usuários, e discutir a utilização desta ferramenta, a fim de identificar possíveis melhorias na mesma e no processo de contratualização no âmbito da gestão pública em saúde. Um questionário foi enviado aos usuários cadastrados na ferramenta contendo questões abertas e de múltipla escolha para alcançar este objetivo e buscar entender as dificuldades encontradas pelos mesmos.

O restante deste trabalho está organizado da seguinte forma: na seção 2, apresentamos como solução foi pensada diante do seu contexto; na seção 3 , detalhamos o processo de desenvolvimento da arquitetura, bem como os requisitos funcionais e não funcionais; na seção 4, discutimos o estado atual da ferramenta e o seu viés burocrático; por fim, na seção 5, discorremos sobre as conclusões e trabalhos futuros.

\section{ALINHANDO O DOMÍNIO DO PROBLEMA E A SOLUÇÃO}

O SIMAIES foi desenvolvido para dar suporte ao processo de monitoramento e avaliação dos COAPES. Para a construção e manutenção de um contrato/convênio, é necessário que cada um dos atores envolvidos contribua com algumas informações.

No escopo do SIMAIES estes são os possíveis tipos de usuários:

1) Gestor coordenador, responsável por criar a pactuação e definir os demais partícipes do contrato, além de monitorar a evolução do contrato/convênio. Partícipes ou participante é a forma de chamar os municípios e instituições formadoras associadas a um contrato;

2) Gestor participante, atua como representante de um município, sendo responsável por vincular instituições formadoras aos estabelecimentos de saúde locais e anexar planos de contrapartida. Gestor coordenador e gestor participante, são papéis desempenhados por servidores da administração pública designados pela Secretaria de Municipal de Saúde;

3) Representantes de instituições formadoras, responsáveis por criar e gerenciar os planos de atividade no sistema;

4) Membros da comissão executiva que são responsáveis por aprovar a solicitação de cadastro de um gestor coordenador, alterar o coordenador de alguma pactuação e responder dúvidas sobre como utilizar o sistema. Este papel é de responsabilidade dos consultores técnicos vinculados ao Ministério da Saúde; e

5) Cidadãos, usuários que não necessitam de cadastro. Este papel é normalmente desempenhado pela a população em geral, que pode consultar os dados públicos dos contratos/convênios.

Na Figura 1, é possível visualizar um modelo de processo que ilustra a sequência das atividades principais para a definição de um contrato/convênio. 
1) Inicialmente, o gestor coordenador realiza seu cadastro no sistema. Após isso, algum dos membros da comissão executiva deverá analisar essa solicitação e validá-la, lendo os documentos (anexados no cadastro) comprobatórios de identidade e permissões daquele gestor.

Caso todas as informações tenham procedência, o acesso ao sistema será liberado.

2) Depois que o gestor coordenador for validado, ele poderá iniciar a definição do contrato/convênio. Para isso, o gestor coordenador deve informar quais os municípios e

instituições formadoras compõem a pactuação e qual o email dos seus representantes. Esse email será usado pelo sistema para a criação de novos usuários (gestores e representantes de instituições formadoras). O SIMAIES enviará para cada um dos emails cadastrados as credenciais de acesso (usuário e senha), além de orientar como deve ser feito o correto preenchimento dos outros dados pessoais do usuário (CPF, RG, telefone e comprovantes).

3) O próximo passo é vincular às instituições formadoras do contrato/convênio aos estabelecimentos de saúde do município. Essa é uma ação que pode deve ser executada por pelo gestor participante.

4) Após as contribuições dos gestores, cabe agora aos representantes das instituições formadoras participantes criar e preencher os planos de atividade. Estes planos descrevem o período de vigência de uma atividade, o número de docentes/discentes/residentes envolvidos, a carga horária, dentre outras informações. Para cada disciplina ofertada ou ação desenvolvida a escopo municipal, o representante deve criar um novo plano de atividade.

5) Gestores participantes e coordenador podem submeter os planos de contrapartida. Estes planos são desenvolvidos através da colaboração das instituições formadoras com o município, definindo uma série de compromissos e objetivos que ambas as partes irão se submeter.

6) Simultaneamente ou independente do item anterior, o coordenador fará a análise dos planos de atividade cadastrados. Caso seja aprovado, o plano será automaticamente publicado e ficará disponível para a consulta na área pública do SIMAIES.

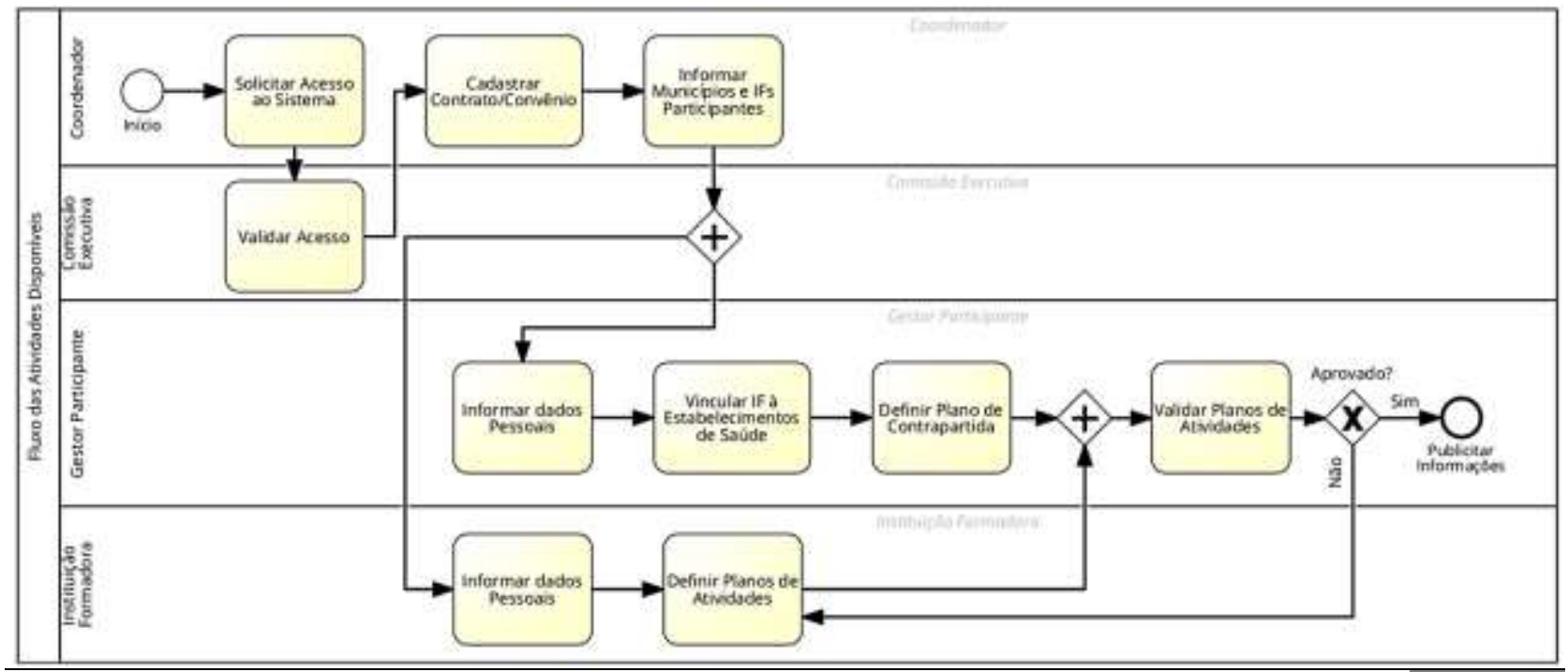

HOLOS, Ano 35, v.2, e7637, 2019 
Figura 1: Modelo de processo que ilustra a sequência das atividades principais do SIMAIES.

$\mathrm{Na}$ área pública do sistema, o cidadão pode consultar os contratos/convênios vigentes, filtrando-os por unidade federativa e/ou município. É possível também conferir as leis e portarias referentes ao COAPES, ter acesso às últimas notícias relevantes ao sistema, sanar as dúvidas mais frequentes sobre os contratos organizativos e consultar os materiais de apoio, como por exemplo, o manual do sistema. Além disso, é na área pública que os gestores coordenadores solicitam seu primeiro acesso. Na área pública também há um canal de comunicação para que o usuário possa contatar tanto a equipe de suporte quanto a comissão executiva.

$\mathrm{Na}$ área privada, restrita a gestores e representantes, os usuários (de acordo com as suas permissões) podem realizar as ações necessárias para a manutenção dos contratos/convênios. Entre elas, há: cadastrar/atualizar planos de atividade e contrapartida; adicionar novos municípios e instituições formadoras à pactuações já criadas; alterar o coordenador de uma determinada pactuação; cadastrar e/ou convidar novos usuários para representar partícipes de um contrato/convênio já existente, além de listar todos os membros envolvidos nessa pactuação.

Ambas as áreas foram estruturadas tomando como base as recomendações do Portal Padrão Institucional de Referência, que é o modelo padrão definido pelo Governo Federal Brasileiro.

\section{SIMAIES: REQUISITOS, ARQUITETURA E INTERFACE COM USUÁRIO}

O desenvolvimento do SIMAIES iniciou-se com um estudo aprofundado do problema que ele visa solucionar. As seguintes perguntas deram norte ao processo de desenvolvimento e definição da arquitetura deste sistema de monitoramento: Quem são os possíveis interessados neste sistema e como se caracterizam? Quais serviços o sistema deve prover? Que tecnologias, dentre as disponíveis, podem ser utilizadas? Como será realizada a interação com o usuário? Como as informações dos contratos/convênios gerados serão divulgadas para o público?

Esta seção visa mostrar as respostas encontradas pela equipe de desenvolvimento a essas perguntas, além de explicar o motivo por trás de cada escolha.

\subsection{Requisitos}

Conhecer os interessados no sistema e suas necessidades é essencial para definir os requisitos que o sistema oferecerá. Requisitos são condições e capacidades fornecidas pelo software para que o usuário cumpra com um determinado objetivo, além de especificar os processos da organização e demais componentes do sistema (LEITE, 2000).

Para o desenvolvimento do SIMAIES uma equipe do Ministério da Saúde foi destacada para levantar as principais necessidades das partes envolvidas (gestores municipais, instituições formadoras, estabelecimentos de saúde e população) e repassar para a equipe de desenvolvimento, gerando assim os requisitos iniciais do sistema. Tradicionalmente eles estão divididos em requisitos funcionais e não funcionais. Abaixo estão listados alguns deles, todos já implementados e considerados essenciais para a execução do SIMAIES. 


\subsubsection{Requisitos funcionais}

Os requisitos funcionais descrevem as funcionalidades que os clientes e usuários esperam encontrar no sistema. Eles indicam o escopo do projeto, definindo as tarefas e serviços que devem ser oferecidas pela aplicação (VASQUEZ e SIMÕES, 2016).

O SIMAIES foi desenvolvido a partir dos seguintes requisitos funcionais:

- Criar contrato/convênio: o coordenador pode criar uma nova pactuação, fornecendo uma lista de partícipes (municípios e instituições formadoras).

- Acompanhar execução de contrato/convênio: o coordenador pode acessar todas as informações referentes a sua pactuação, desde partícipes até os arquivos anexados, como planos de contrapartida, planos de atividade, comprovantes e declarações.

- Associar estabelecimento de saúde à instituição formadora: ao firmar o contrato/convênio, os gestores devem vincular uma unidade de saúde a uma instituição de ensino, possibilitando que planos de atividade e planos de contrapartida possam ser adicionados a pactuação no futuro.

- Aprovar planos de atividade e contrapartida: depois de conferir todas as informações e verificar se elas estão corretas, o coordenador pode aprovar os planos de atividade e/ou planos de contrapartida selecionado para que eles se tornem vigentes na pactuação escolhida.

- Cadastrar instituição formadora: em situações nas quais uma determinada instituição formadora não fizer parte do banco de dados do sistema, o gestor do contrato pode fornecer as informações necessárias no formulário para cadastrá-la.

- Cadastrar gestor coordenador: um usuário (não autenticado) pode solicitar seu acesso ao sistema como gestor do SUS na área pública do sistema, informando os dados solicitados pelo formulário "Cadastrar Gestor Coordenador". Após isso, sua solicitação deve ser analisada pela Comissão Executiva e cabe a ela autorizar ou não.

- Realizar download dos materiais de apoio: qualquer usuário deve ter acesso às seções "Materiais de Apoio", "Legislação" e "Perguntas Frequentes". Nelas devem estar disponíveis o manual de uso do sistema, modelo de autorização de representação no SIMAIES, documentos contendo respostas às dúvidas consideradas mais triviais e as leis e portarias relacionadas ao COAPES.

- Entrar em contato com a comissão executiva ou equipe técnica: caso surja a necessidade, o usuário (autenticado ou não) deve encontrar à sua disposição um formulário onde é possível informar um assunto (tanto para a comissão executiva quanto para a equipe técnica) e submetê-lo. Um e-mail será enviado para os responsáveis e eles farão o contato com esse usuário assim que possível.

- Buscar contrato/convênio: qualquer usuário pode buscar na área pública do sistema as pactuações firmadas que já possuem planos de atividade e contrapartida aprovados/vigentes, podendo filtrar os resultados por unidade federativa e/ou município. 
Os resultados da busca incluem a possibilidade de visualizar todos os partícipes e seus respectivos planos.

\subsubsection{Requisitos não funcionais}

Os requisitos não funcionais definem quais atributos de qualidade e restrições devem ser satisfeitas pelo software (CYSNEIROS e LEITE, 1997).

O SIMAIES foi planejado de acordo com os seguintes requisitos não funcionais:

- Usabilidade: O sistema deve ter o seu visual construído em cima do Portal Padrão do Governo Federal (um modelo de cores, fontes, menus e etc. para a construção de um site do governo) para que sua identidade visual seja facilmente reconhecida e a interação com o usuário aconteça de forma intuitiva, lógica e fácil. Deve possuir menus informativos de ajuda e manual de acesso disponível ao usuário.

- Confiabilidade: Informações referentes aos valores e resultados gerados após a execução das ações do sistema devem ser precisas. O SIMAIES deve ter a capacidade para tratar falhas e/ou se recuperar delas. O usuário não deve ver mensagens de erro que revelem informações sobre o sistema (versão do banco, nomes de arquivo ou usuários, etc.).

- Compatibilidade: O sistema, por se tratar de uma aplicação web em arquitetura cliente/servidor, poderá ser acessado por navegadores (Google Chrome, Mozilla Firefox, Internet Explorer, Safari, etc.) nos sistemas operacionais Windows, Linux e iOS. O comportamento das funcionalidades deve ser o mesmo.

\subsection{Arquitetura}

Antes de iniciar o desenvolvimento do sistema, selecionamos o GitLab como plataforma para controle de versão de arquivos. O sistema foi desenvolvido utilizando o PHP (acrônimo recursivo para "PHP: Hypertext Preprocessor", em inglês) como linguagem de programação. Essa escolha foi realizada visando permitir a futura integração e hospedagem do SIMAIES no DATASUS (Departamento de Informática do SUS), o qual hospeda atualmente apenas sistemas desenvolvidos em Java ou PHP.

Para tornar o desenvolvimento ainda mais rápido, além da linguagem de programação, os desenvolvedores optaram pela utilização de frameworks. Estes são construídos com classes e objetos que colaboram entre si para fornecer solução à uma família de problemas semelhantes, tendo flexibilidade para possibilitar, com pouco esforço, a construção de várias aplicações baseadas nessas classes (SAUVÉ, 2016). Existe uma gama de frameworks desenvolvidos para o PHP, tais como o Laravel, CakePHP, Symphony, Codelgniter, Phalcon Zend e Yii. Para o desenvolvimento do SIMAIES a equipe optou por utilizar o Laravel, eleito em 2015 pelo Sitepoint como o melhor framework para PHP (Skvorc, 2015).

O framework escolhido segue o MVC (Model-View-Controller) como padrão de arquitetura de software. Este padrão determina a separação de uma aplicação em três camadas que mantém uma comunicação entre si, com o Model atuando como conjunto de entidades que representam os dados da aplicação; a View sendo responsável por lidar com as partes gráficas (requisição e 
exibição dos dados do Model) e o Controller conectando os elementos do Model com a View. Isso inclui tratamento de eventos e geração de exceções, além da alteração dos elementos contidos na View para refletirem a nova forma dos dados (Krasner e Pope, 1998).

Quanto ao SGBD (Sistema Gerenciador de Banco de Dados), a equipe de desenvolvimento do SIMAIES optou pelo PostgreSQL. A escolha foi motivada tanto por fatores locais quanto por fatores técnicos. Para os fatores locais, levou-se em consideração que a equipe de desenvolvimento já estava familiarizada com o sistema e havia uma comunidade formada no ambiente de trabalho já capacitada e pronta para oferecer suporte nas questões de implementação. Para os fatores técnicos, considerou-se que o PostgreSQL é gratuito para usar e tem seu código fonte aberto e disponível para a comunidade de desenvolvedores. Além disso, possui um grande ecossistema de extensões, tais como o Citus, que permite transformar o PostgreSQL em um banco de dados distributivo e o PostGIS que permite adicionar novos tipos de dados geoespaciais avançados (KERSTIENS, 2017).

\subsection{Interface com o Usuário}

Nesta subseção, apresentamos a interface humano-computador e como ocorre a interação do usuário com o sistema através da realização das seguintes atividades: Realizar Login, Listar Pactuações Disponíveis, Detalhar Contrato/Convênio, Listar Planos de Atividade, Detalhar um Plano de Atividade e Definir Plano de Atividade, respectivamente.

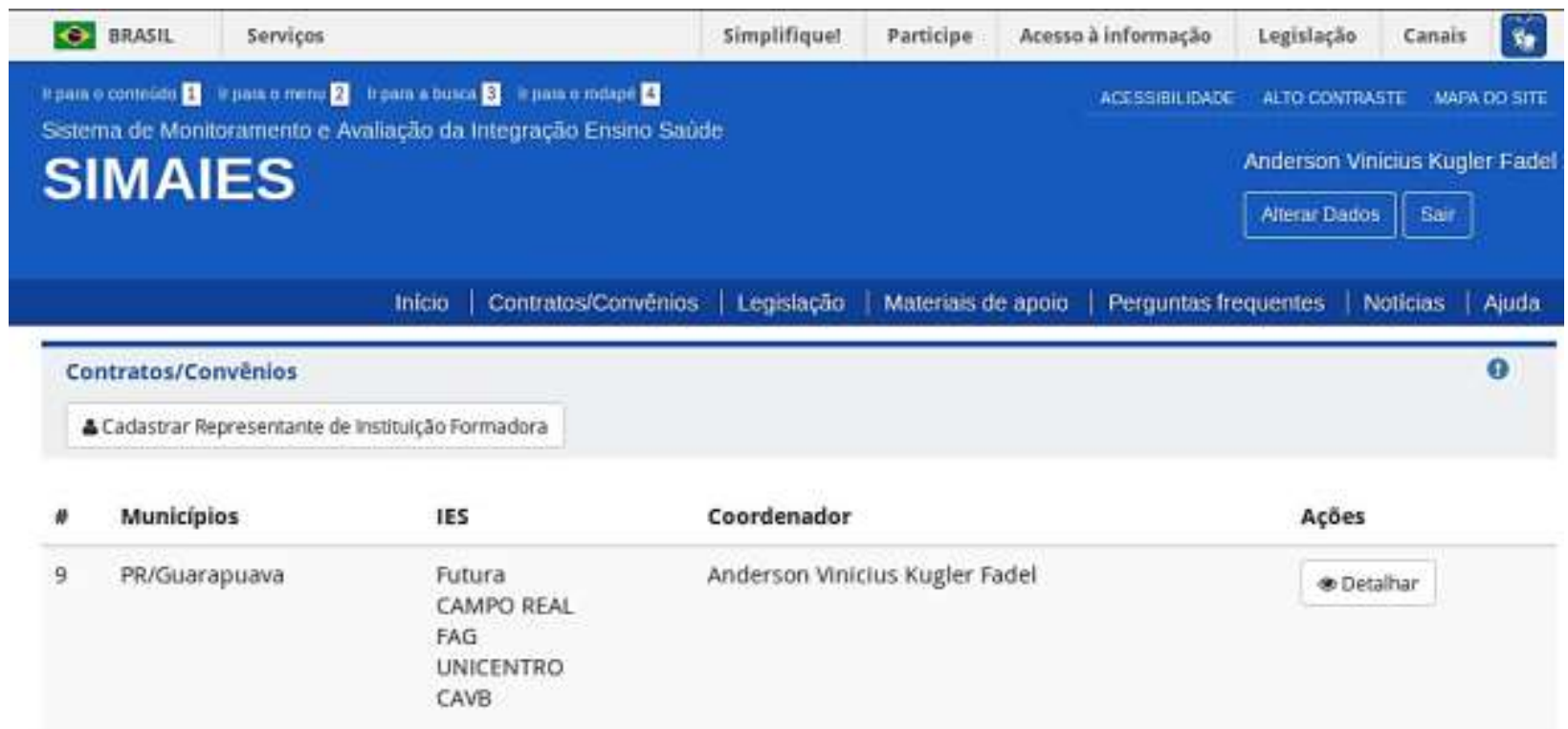

Figura 2: Tela Inicial e Listagem de Pactuações Disponíveis.

Na Figura 2, vemos a tela para qual o usuário é redirecionado logo após ter realizado o seu login. Este cabeçalho contendo o nome do sistema, a barra do governo federal e o menu de acesso às páginas do site está presente em todas as outras telas. 
Nela, os gestores participantes e representantes das instituições formadoras podem visualizar apenas o seu contrato/convênio. Uma breve informação sobre a pactuação é fornecida, exibindo os partícipes e o gestor coordenador.

Cabe ao usuário selecionar qual contrato/convênio ele deseja obter informações mais detalhadas clicando em "Detalhar", na coluna "Ações".

\begin{tabular}{|c|c|c|c|c|c|c|}
\hline \multicolumn{3}{|l|}{ Detalhamento de contrato/convênio } & & & & (9) \\
\hline Inserir novos municipios e/ou Instituiçōes Formadoras & 巠 Vincu & jestores e Representantes & s \&Vincular IF a Serviço d & Saúde & «్ㅇㅇ Usuários & כVoltar \\
\hline \multicolumn{7}{|c|}{ Coordenador: MARINA DE FÁTIMA DE OLIVEIRA Gestor Municipal: SP/Bragança Paulista } \\
\hline \multicolumn{2}{|l|}{ Instituições Formadoras } & Município & \multicolumn{4}{|c|}{ Ações } \\
\hline \multicolumn{2}{|c|}{$\begin{array}{l}\text { CURSO PROFISSIONALIZANTE BRAGANTINO - ESCOLA NOVA } \\
\text { BIOTEC (BIOTEC) }\end{array}$} & SP/Atibaia & \$ Plano de contrapartida & \multicolumn{2}{|c|}{ Planos de atividade } & \\
\hline \multicolumn{2}{|l|}{ ESCOLA MADRE PAULINA LTDA ME (MADRE PAULINA) } & SP/Atibaia & \$Plano de contrapartida & \multicolumn{2}{|c|}{ Planos de atividade } & \\
\hline \multicolumn{2}{|c|}{$\begin{array}{l}\text { FACULDADE DE CIÊNCIAS E LETRAS DE BRAGANÇA PAULISTA } \\
\text { (FESB) }\end{array}$} & SP/Atibaia & \$ Plano de contrapartida & \multicolumn{2}{|c|}{ Planos de atividade } & \\
\hline
\end{tabular}

Figura 3: Detalhamento de Contrato/Convênio.

A Figura 3 ilustra o detalhamento de um contrato/convênio, que pode ser acessado tanto por gestores participantes quanto gestores coordenadores. Nessa interface estão listados os partícipes da pactuação selecionada. Para cada instituição formadora e município participante existem os botões "Plano de contrapartida" e "Planos de atividade". No primeiro, o gestor participante pode anexar um novo plano ou acessar o existente. No segundo, ele visualiza uma lista contendo todos os planos de atividade vinculados, podendo visualizá-los, bem como selecionar quais ele quer aprovar ou reprovar.

Essa figura mostra também, na parte superior, um menu de outras ações que podem ser realizadas pelos gestores nesta pactuação: "Inserir novos municípios e/ou Instituições Formadoras", para adicionar partícipes à pactuação; "Vincular Gestores e Representantes", quando houver partícipes sem um gestor responsável; "Vincular IF a Estabelecimento Saúde", para atribuir uma instituição formadora a um estabelecimento de saúde; "Usuários", para conferir as informações dos usuários participantes do contrato/convênio (nome, e-mail, se está ativo ou inativo no sistema, municípios/instituições que representam), além de verificar o histórico de coordenadores da pactuação.

$\mathrm{Na}$ Figura 4 é possível visualizar a lista de planos de atividades inseridos para um determinado contrato. Nela são listados os municípios, estabelecimentos de saúde, instituições de ensino (instituição formadora), tipo de ensino (ensino técnico, graduação ou residência), curso/especialidade e situação (aprovado ou reprovado). Além disso, por meio do link "Detalhar", o usuário pode visualizar mais informações acerca de um plano de atividade escolhido, como 
mostrado na Figura 5. Essas informações incluem, entre outras, quantidade de discentes e docentes, a ementa da disciplina, seus objetivos e atividades a serem desenvolvidas.

Coordenador: MARINA DE FȦTIMA DE OLIVEIRA

\section{Planos de atividade}

\begin{tabular}{|c|c|c|c|c|c|c|}
\hline Municiplo & Estabelecimento de Saude & IES & $\begin{array}{l}\text { Graduaçdo ou } \\
\text { Residencia }\end{array}$ & Curso/Especialide & $\begin{array}{l}\text { Status da } \\
\text { aprovaço o } \\
\text { pelo gestor }\end{array}$ & Ăَ̧̧o \\
\hline $\begin{array}{l}\text { SP/Bragança } \\
\text { Paulista }\end{array}$ & $\begin{array}{l}\text { UPA UNIDADE OE PRONTO ATENDIMENTO } \\
\text { 24H BRAGANCA PAULISTA }\end{array}$ & BIOTEC & Ensino Técnico & - & Aprovado & Detalhar \\
\hline $\begin{array}{l}\text { SP/Bragança } \\
\text { Paulista }\end{array}$ & $\begin{array}{l}\text { UPA UNIDADE DE PRONTO ATENDIMENTO } \\
24 H \text { BRAGANCA PAULISTA }\end{array}$ & BIOTEC & Ensino Técnico & - & Aprovado & Detalhar \\
\hline $\begin{array}{l}\text { SP/Bragança } \\
\text { Paulista }\end{array}$ & ESF CASA DEJESUS & USF & Graduaçăo & Medicina & Aprovado & Detalhar \\
\hline $\begin{array}{l}\text { SP/Bragança } \\
\text { Paulista }\end{array}$ & ESF CASA DEJESUS & USF & Graduaçăo & Medicina & Aprovado & Detalhar \\
\hline $\begin{array}{l}\text { SP/Bragança } \\
\text { Paulista }\end{array}$ & $\begin{array}{l}\text { SAMU } 192 \text { REGIONAL BRAGANCA } \\
\text { PAULISTA }\end{array}$ & BIOTEC & Ensino Técnico & - & Aprovado & Detalhar \\
\hline
\end{tabular}

Figura 4: Listagem de Planos de Atividade.

(5) Detalhes do plano de atividades entre BIOTEC E UPA UNIDADE DE PRONTO ATENDIMENTO 24H BRAGANCA PAULISTA

$\begin{aligned} \text { Período: } & 21 / 06 / 2017 \text { a } 16 / 08 / 2017 \\ \text { Titulo: } & \text { Urgéncia e tmergència } \\ \text { Campo de pratica: } & \text { Ensino Tecnico } \\ \text { Formaçōes Residenci... } & \\ \text { Curso de graduaçäo: } & \text {. } \\ \text { Tipos de atividades: } & \text { Disciplina obrigatoria }\end{aligned}$

Sümula/ementa da disciplina/atividade no curriculo:

- Prestar assistencia de Enfermagem e auxilio as equipes nas urgencias; Monusear os equipamentos especificos do setor: Aplicar normas gerais de prestaça setor, Aplicar normas gerais de prestacao Socorros: Socorros; - Competencias; - NR 32, NR 6; Controlar materiais na unidade; - Recursos de atendimento de emergenclas
disponiveis: - Controte de infecção: Limpeza e desinfecçāo de materiais e equipamentos.

Docentes/Preceptores:

Rosana Goes - novabiotec@iotmail.com - 1140325548

Arquivos Complementares:

Figura 5: Detalhamento de um Plano de Atividade.

Cabe aos representantes das instituições formadoras participantes definirem e manterem os planos de atividade no SIMAIES. Isso é realizado por meio de um formulário, que se adapta de acordo com o "campo de prática" (Graduação, Residência Médica, Residência Multiprofissional, 
Pós-graduação, Ensino Técnico) a ser selecionado. Após a definição de um plano de atividade, ele permanece com o status Pendente até que o gestor coordenador daquele contrato/convênio o aprove ou reprove.

\section{DISCUSSÃO}

Depois de constantes evoluções considerando não só os requisitos funcionais necessários, mas também aspectos de usabilidade e confiabilidade, o SIMAIES foi disponibilizado aos seus usuários durante o segundo semestre de 2016. Estando acessível à comunidade brasileira, ele tem sido discutido em oficinas promovidas pelo Ministério da Saúde e conferências sobre o tema educação, política e atenção à saúde.

O sistema conta atualmente com 6 contratos cadastrados, distribuídos entre 21 municípios e 33 instituições formadoras. Além disso, há 61 usuários, dos quais 33 usuários já realizaram login, ou seja, acessaram o sistema utilizando suas próprias credenciais (email e senha), e outros 28 que nunca acessaram o sistema informando suas credenciais. Estes 28 usuários são do tipo Representante de Instituição Formadora ou Gestor Participante, o que significa que seus emails de contato foram informados por um Gestor Coordenador e não pelo próprio usuário. Dentre os 33 usuários ativos que já acessaram o sistema, 4 são Membros da Comissão Executiva, ou seja, não gerenciam contratos, mas gerenciam o sistema em si, dando acesso aos Gestores Coordenadores, além de possuir permissão para alterar o coordenador de algum contrato e responder dúvidas sobre como utilizar o sistema. Assim, temos efetivamente 29 usuários ativos que gerenciam contratos e que já acessaram o sistema pelo menos uma vez.

\subsection{Pesquisa Qualitativa}

Realizamos uma pesquisa qualitativa com o intuito de entender, do ponto de vista dos usuários, quais as vantagens e desvantagens na utilização do SIMAIES e quais as principais dificuldades que os mesmos têm enfrentado ao utilizá-lo. Em meados de Março deste ano, foi enviado um email para todos os usuários cadastrados com solicitação para que respondessem uma pesquisa sobre a utilização do SIMAIES. O questionário foi criado utilizando no Google Forms e ficou disponível por uma semana, sendo constituído pelas questões mostradas na Figura 6. 


\section{Pesquisa de Análise do Uso do SIMAIES \\ O objetivo desta pesquisa e analisar e entender como o Simales esto sendo utitzado peios emotidos nos COAPES, quais as principels dificuldades e sugestces de mehoris. \\ As perguntas aboxo reterern se a sua reloçlo com o caApts. \\ *otrigatatio \\ Qual o seu email? \\ informe o email cadastrado no Simaies, caso já tenha utilizsdo o sistema. \\ Sua resposto \\ Qual sua UF? * \\ informe o nome cu sigla do seu estado \\ Sua resposto}

Qual a sua Cidade? *

Sua resposta

Qual seu papel em relação ao COAPES? *

Gestor Municipal

Representante de Institulçäo de Ensino

Representante de Estabelecimento de Saùde

Outro:

Qual instituição/órgão você representa? *

Informe o nome do municipio, Inatihuiç5o de Ensina, Ertabeiecimento de Saude cu outro que se aplique.

Sua resposta

Como ficou sabendo da ferramenta SIMAIES? *
Vocẽ está vinculado a algum contrato que nāo está inserido no SIMAIES?

( $\operatorname{Sim}$

Não

Caso a resposta anterior tenha sido 'Sim', por quê o contrato nâo foi inserido no Simaies?

Sua tespouta

Na sua opinião, quais as VANTAGENS de se utilizar o sistema para registrar um contrato/convênio?

Sua sespostil

Na sua opiniẵo, quais as DESVANTAGENS de se utilizar o sistema para registrar um contrato/convênio?

Sua respostil

Quais as dificuldades enfrentadas com o uso do SIMAIES? *

NJo consigo acessar o sistema

O sisterna é pouco intultivo

Os demais gestores do sistema ndio interagem com meu contrato

Ainda faltam informaçoses para que meu contrato seja atualizado no sistema

Outro:

Você sabia que existe um curso gratuito no Avasus que ensina a usar o Simaies? *

- Sim

Näo

Figura 6: Questionário enviado aos usuários cadastrados no SIMAIES.

Dentre os 61 usuários cadastrados, 10 responderam à pesquisa, sendo 5 usuários do tipo Gestor Coordenador, 4 Representantes de Instituição Formadora e 1 Coordenador Participante. Todos os usuários respondentes estão vinculados a um contrato no SIMAIES.

Com relação às vantagens da utilização do sistema, os usuários destacaram os seguintes pontos: V1) A transparência e publicidade, uma vez que permite que a população tenha conhecimento destes acordos envolvendo municípios, instituições formadoras e estabelecimentos de saúde; V2) O ambiente centralizador de informações, o que poderá, com a continuidade e ampla utilização da ferramenta, gerar relatórios estatísticos, determinando por exemplo quais regiões do país carecem desse tipo de contrato/convênio. Além disso, é possível ter uma ideia de como estão distribuídos os estagiários, residentes e pesquisadores das instituições formadoras; e V3) O 
monitoramento, controle e avaliação do processo de forma a padronizar o fluxo de trabalho em todas as regiões.

As desvantagens e dificuldades com relação à utilização do sistema foram as citadas a seguir: D1) O sistema é pouco intuitivo; D2) Não existem relatórios disponíveis aos gestores, apenas listagem de registros cadastrados (planos de atividades e de contrapartida); D3) O sistema não permite exclusão de registros (registros cadastrados erroneamente devem ser comunicados ao Administrador do Sistema, para posterior remoção); D4) A necessidade da interação entre as pessoas envolvidas para que o fluxo do processo chegue ao fim.

É notória a pouca quantidade (6) de contratos registrados no SIMAIES, bem como uma pequena base de usuários utilizando o sistema. Isto pode ser sanado com uma maior divulgação por parte do Ministério da Saúde, seja em oficinas e conferências ou através de uma campanha em seu site.

As desvantagens D1 e D2 mencionadas, estão atualmente sendo analisadas pela equipe técnica do SIMAIES em conjunto com os membros da Comissão Executiva. Para resolver o problema do item D3, está sendo implementada a exclusão lógica do registro, ou seja, a informação não aparece para o usuário, mas continua no banco de dados para o caso de necessidade de recuperação posterior (nos casos em que a exclusão foi realizada por engano, por exemplo).

Apesar de todo o esforço para o desenvolvimento de uma ferramenta que apoie a gestão virtual dos contratos criados a partir do COAPES, ainda existe um caminho burocrático a ser percorrido antes da utilização do SIMAIES (citado como dificuldade no D4). Os acordos entre os representantes das instituições formadoras e das unidades de saúde devem ser iniciados fora da ferramenta. Essas negociações podem demorar semanas ou meses, uma vez que dependem da disponibilidade de gestores e da árdua tarefa de levantar as informações necessárias para realizar a pactuação e sua posterior inserção no sistema.

\section{CONCLUSÃO}

Neste trabalho apresentamos o Sistema de Monitoramento e Avaliação da Integração Ensino Saúde. Uma ferramenta que apoia o registro de contratos/convênios entre Instituições formadoras e de saúde, e principalmente que promove a transparência de informações sobre os convênios existentes. Com isso, o sistema incentiva a relação ensino-serviço-comunidade, otimizando o processo de avaliação e monitoramento das atividades desta integração.

Através de uma pesquisa qualitativa com os usuários do sistema procuramos entender, do ponto de vista dos usuários, quais as vantagens e desvantagens na utilização do sistema e as principais dificuldades. O resultado desta pesquisa mostrou que o SIMAIES atende o seu propósito principal (monitorar e avaliar a contratualização e integração ensino-saúde), mas carece de maior divulgação a fim de que seja amplamente utilizado em todo território nacional.

Apesar da automatização trazida pela ferramenta, ainda há um fluxo burocrático a ser percorrido antes da utilização do sistema, o que pode trazer alguma morosidade ao processo. Em uma futura implementação, a equipe de desenvolvimento analisa a possibilidade de obter as bases de dados de todos os gestores municipais atualizadas, bem como instituições formadoras e 
estabelecimentos de saúde, a fim de proativamente buscar firmar essas parcerias ou incitar o contato mútuo para que a pactuação se realize de maneira mais ágil.

\section{REFERÊNCIAS BIBLIOGRÁFICAS}

MINISTÉRIO DA SAÚDE. (2015). Manual de Apoio aos Gestores do SUS para implementação do COAPES. Brasília: Editora MS. p. 5.

PIZZINATO, A. et al. (2012). "A Integração Ensino-Serviço como Estratégia na Formação Profissional para o SUS." Revista Brasileira de Educação Médica, v. 36, p. 170-177.

PORTAL DA SAÚDE. SIMAIES irá qualificar e monitorar acordos entre gestores e instituições de ensino. Disponível em: $<$ http://portalsaude.saude.gov.br/index.php/oministerio/principal/secretarias/sgtes/noticiassgtes/23645-simaies-ira-qualificar-e-monitoraracordos-entre-gestores-e-instituicoes-de-ensino>. Acesso em: 02 abr. 2017.

SIMÕES, J. C. (2011, out.). No Brasil faltam médicos: mito ou realidade? Revista do Médico Residente, Paraná, 13 (4), p.221-222. Trimestral. Disponível em: $<$ http://crmpr.org.br/publicacoes/cientificas/index.php/revista-domedicoresidente/article/view/118/118>. Acesso em: 03 maio 2017.

Mais Médicos. (2015). COAPES pode beneficiar mais de 1 milhão de estudantes da saúde. Disponível em: <http://maismedicos.gov.br/noticias/149-coapes-podera-beneficiar-mais-1milhao-deestudantes-da-area-da-saude>. Acesso em: 03 maio 2017.

Agência de Minas. (2016). Secretaria de Saúde assina contratos para incentivar a residência médica no estado. Disponível em: <http://www.agenciaminas.mg.gov.br/noticia/secretaria-de-saudeassina-contratos-paraincentivar-a-residencia-medica-no-estado>. Acesso em: 09 maio 2017.

PHP Group. (2017). O que é o PHP? Disponível em: <https://secure.php.net/manul/pt_BR/intro-whatis.php>. Acesso em: 27 de setembro de 2017.

SCHROEDER, K. (2012). Ten Reasons to Use PHP For Your Mobile Project. Eschrade. Disponível em: <http://www.eschrade.com/page/10-reasons-to-use-php-for-your-mobileproject/>. Acesso em 27 de setembro de 2017.

Skvorc, B. (2015). The Best PHP Framework for 2015: SitePoint Survey Results. Disponível em: <https://www.sitepoint.com/best-php-framework-2015-sitepoint-survey-results/>. Acesso em 28 de setembro de 2017.

LEITE, J. C. (2000). Notas de Aula de Engenharia de Software. Dimap. Disponível em: <https://www.dimap.ufrn.be/ jair/ES/c4.html>. Acesso em 29 de setembro de 2017.

SAUVÉ, Jacques Philippe. O que é um framework? UFCG. Disponível em: <https://www.dsc.ufcg.edu.br/ jacques/cursos/map/html/frame/oque.htm>. Acesso em 29 de setembro de 2017. 
CYSNEIROS, L. M.; LEITE, J. C. S. do P. (1997). Definindo Requisitos Não Funcionais. UFMG. Disponível em: <http://www.lbd.dcc.ufmg.br/colecoes/sbes/1997/004.pdf>. Acesso em 30 de setembro de 2017.

KERSTIENS, C. (2017). Why Use Postgres (Updated for Last 5 Years). Craig Kerstiens. Disponível em: <http://www.craigkerstiens.com/2017/04/30/why-postgres-five-years-later/>. Acesso em $1 \mathrm{de}$ novembro de 2017.

KRASNER, G. E; POPE, S. T. (1988). A cookbook for using the model view controller user interface paradigm in smalltalk-80. Journal of Object-Oriented Programming,, p. 26 - 49.

VAZQUEZ, C.; SIMÕES, G. (2016). Engenharia de Requisitos: Software Orientado ao Negócio. Brasport. 